\title{
How does the surface free energy influence the tack of acrylic pressure-sensitive adhesives (PSAs)?
}

\author{
Arkadiusz Kowalski, Zbigniew Czech, \\ Eukasz Byczyński
}

(C) The Author(s) 2013. This article is published with open access at Springerlink.com

\begin{abstract}
This article describes a comparative study of the tack properties of a model acrylic pressuresensitive adhesive (PSA) crosslinked using aluminum acetylacetonate on several substrates, including stainless steel, glass, polyethylene, polypropylene, polytetrafluoroethylene, polycarbonate, and poly(methyl methacrylate). The tack measurements were conducted using a technique commonly used to measure the tack of an adhesive tape in the PSA industries. The surface free energy (SFE) values of the materials were evaluated using the Owens-Wendt and van OssChaudhury-Good methods. The experiments showed a clear relationship between the SFE of the substrate and the tack of the model acrylic PSA. In general, larger differences between the SFE values of the substrate and adhesive $\left(\Delta_{\mathrm{SFE}}\right)$ were correlated with greater tack values. The tack of the model acrylic PSA was found to be optimal over the $\Delta_{\mathrm{SFE}}$ range of $7.0-13.1 \mathrm{~mJ} / \mathrm{m}^{2}$. The trend in the tack as a function of the SFE difference was attributed to the quantity of energy dissipated at the jointed points during the separation stage in the loop tack test.
\end{abstract}

Keywords Surface free energy (SFE), Tack, Acrylic pressure-sensitive adhesives (PSAs), Thermodynamic work of adhesion, Viscoelastic dissipation

A. Kowalski $(\bowtie)$, Z. Czech

Institute of Organic Chemical Technology, West

Pomeranian University of Technology, Szczecin, Poland

e-mail: sputnik5@wp.pl

Ł. Byczyński

Department of Polymer Science, Rzeszów

University of Technology, Rzeszow, Poland

\section{Introduction}

Pressure-sensitive adhesives (PSAs) are unique in that they form a strong bond under relatively light pressure over short contact times. PSAs immediately grab onto a substrate (the material to which the PSA is applied) without the need for activation agents (e.g., heat, water, solvent, etc.). Among the various classes of adhesives, PSAs are possibly the most common adhesive found in consumer products. Self-adhesive tapes and labels of all kinds are ubiquitous in everyday life. Synthetic polymers based on acrylics, silicones, polyurethanes, or rubbers are preferred adhesive materials for use in commercial PSA systems because they display excellent performance. Acrylics may be optimized for the formulation of a PSA product by tuning certain preparation parameters. Acrylics are typically random copolymers of a long side-chain acrylic [ $n$-butyl acrylate (BA) or 2-ethylhexyl acrylate (2-EHA)] with a low glass transition temperature $\left(T_{\mathrm{g}}\right)$, a short side-chain acrylic, such as methyl acrylate, which tunes $T_{\mathrm{g}}$, and an acrylic acid (AA) that improves adhesion to polar substrates and optimizes the elongation properties of the material. PSAs can be applied as solventborne, waterborne (dispersions), or solvent-free systems. ${ }^{1}$

The three adhesive properties that are most useful for characterizing the nature of a PSA are the tack (initial adhesion), the peel adhesion (adhesion), and the shear strength (cohesion). Tack measures an adhesive's ability to adhere quickly; the adhesion measures the adhesive's ability to resist removal by peeling, and the cohesion measures the adhesive's ability to remain in position under shearing forces. Tack dominates the properties of a PSA and is defined by the American Society for Testing and Materials (ASTM) as the ability of an adhesive to form a bond of measurable strength to another surface under conditions of low contact pressure and short contact time. 
The tack properties may be measured using a variety of testing methods, including the rolling ball tack test, the quick stick tack test, the probe tack test, and the loop tack test. The loop tack test is widely used in the adhesive tape and PSA industries, primarily as a quality control tool. The most popular measurement method is the FINAT Test Method No. 9 and the AFERA $4015 .^{2}$

To be effective, a PSA must immediately wet a surface as soon as it is brought into contact with the surface. The rapid and thorough wetting of a surface by an adhesive film requires that the adhesive material be relatively soft. Dahlquist ${ }^{3}$ found that materials with a dynamic shear modulus (stiffness) of less than $3 \times 10^{6}$ dynes $/ \mathrm{cm}^{2}\left(10^{5} \mathrm{~Pa}\right)$ exhibit tack when deformed over $1 \mathrm{~s}$.

The viscoelasticity of a PSA must fall within a certain range for practical applications; however, viscoelasticity is not the only factor that affects the performance of a PSA. The surface energy also influences the strength of pressure-sensitive adhesion. The surface energy is a measure of an adhesive's ability to wet a surface and adhere. ${ }^{4}$ Adhesion reaches a maximum once the viscoelastic adhesive or PSA tape thoroughly wets the surface to be bonded. Better wetting properties yield a better surface coverage and greater attractive forces between the adhesive and the substrate surface. Better wetting also promotes surface penetration, in which microscopic surface irregularities may be filled in to produce adhesive interlocks that increase the strength of the mechanical bond. ${ }^{5}$

The surface free energy (SFE) is defined as the work needed beyond the magnitude of the forces holding the surfaces together to separate two surfaces. The SFE is given in units of energy per unit area, is often referred to as the surface tension, and may be expressed in units of dynes $/ \mathrm{cm}$ (a surface tension of 1 dyne $/ \mathrm{cm}$ or $1 \mathrm{mN} / \mathrm{m}$ is equivalent to a SFE of $1 \mathrm{~mJ} / \mathrm{m}^{2}$ ). The SFE depends on the interfacial intermolecular forces and comprises the contributions from nonpolar (e.g., van der Waals) and polar (e.g., hydrogen bonding) components. The polar components can be further broken into electron acceptor or electron donor components (or Lewis acid/ base components). Regions of a polar molecule will include a range of acceptor/donor component strengths, and in many regions, one component will be much more significant than the other. The SFE of a solid can be determined only indirectly by measuring the dynamic or static contact angles of various liquids, in combination with appropriate theoretical approaches. ${ }^{6}$ The main methods used to determine the SFE of a solid are the methods of Zisman, OwensWendt (OW), and the relatively new method of van Oss-Chaudhury-Good (vOCG).

Adhesives having an SFE that is less than the SFE of a substrate will readily wet the substrate surface and form strong adhesive bonds. ${ }^{8-10}$ If sufficiently extensive contact is achieved between the substrate and the adhesive, then the physical interactions or bonds that form between the atoms of the two surfaces result in surface wetting. Such physical interactions arise from highly localized intermolecular forces. Wetting may be due to (a) acid-base interactions, (b) the formation of weak hydrogen bonds, or (c) van der Waals forces (dipole-dipole and dispersion forces). The extent of wetting depends on the difference between the SFEs of the substrate and adhesive materials. Wetting occurs spontaneously under the conditions

$\gamma_{\mathrm{sv}} \geq \gamma_{\mathrm{sl}}-\gamma_{\mathrm{lv}}$

where $\gamma_{\mathrm{sv}}, \gamma_{\mathrm{sl}}$, and $\gamma_{\mathrm{lv}}$ are the interfacial SFE at solidvapor, solid-liquid, and liquid-vapor interfaces, respectively. If $\gamma_{\mathrm{lv}}$ is not significant, then this criterion can be simplified to

$\gamma_{\text {sv }} \geq \gamma_{\text {sl }}$ or $\gamma_{\text {substrate }} \geq \gamma_{\text {adhesive }}$

Equation (2) indicates whether an adhesive will spread on the substrate, i.e., when the SFE of the substrate exceeds that of the adhesive. Poor wetting is associated with a lower contact area between the substrate and the adhesive, and more stress regions develop at the interface. Accordingly, the adhesive joint strength decreases. ${ }^{10}$

According to a previous study, ${ }^{11}$ the adhesive forces between an adherent and a PSA will depend on the critical value of the SFE. A maximum tack value may be achieved if the critical surface tension of the substrate is comparable with but slightly greater than the SFE of the adhesive. The measured tack increases as the SFE of the substrate increases until reaching a maximum critical SFE of $33-39 \mathrm{~mJ} / \mathrm{m}^{2}$. Beyond the critical SFE value, the tack decreases.

In this article, we compare the tack of an adhesive on various substrates. Seven substrate materials were tested: stainless steel, polyethylene (PE), polypropylene (PP), polytetrafluoroethylene (PTFE), polycarbonate (PC), poly(methyl methacrylate) (PMMA), and glass. This study presents a systematic investigation of the effects of the substrate SFE on the tack of a model acrylic PSA. The nature of adhesive interactions was explored by investigating the thermodynamic work $\left(W_{\mathrm{a}}\right)$ and the total works $\left(W_{\mathrm{T}}\right)$ associated with adhesion.

\section{Experimental}

\section{Raw materials}

The acrylic PSA was synthesized using the following monomers: butyl acrylate (BA), 2-ethylhexyl acrylate (2-EHA), and acrylic acid (AA). The reaction proceeded in the organic solvent ethyl acetate in the presence of a radical initiator, 2,2'-azo-diisobutyronitrile (AIBN), which initiated the polymerization process. All raw materials are available from BASF 
Germany in Ludwigshafen. The crosslinking agent, aluminum acetylacetonate (AlACA), was purchased from Degussa (Germany). Dehesive silicone paper is available from Laufenberg (Germany).

The dependence of tack on the SFE of the substrate and PSA was examined using the following substrate materials: stainless steel, glass, PE, PP, PTFE, PC, and PMMA. All substrates $(2.5 \mathrm{~cm}$ wide and about $10 \mathrm{~cm}$ long) were obtained from Polymer Institute, West Pomeranian University of Technology, Szczecin, and were characterized as having a smooth surface.

\section{Synthesis of the acrylic PSAs}

Model acrylic PSAs were prepared from $50 \mathrm{wt} \%$ BA, $45.5 \mathrm{wt} \%$ 2-EHA, and $4.5 \mathrm{wt} \%$ AA in ethyl acetate heated to boiling at $78^{\circ} \mathrm{C}$ in the presence of $0.1 \mathrm{wt} \%$ AIBN. The polymerization process was carried out under the following conditions: the monomer blend containing AIBN was added to the ethyl acetate over a period of $1 \mathrm{~h}$. The reaction was allowed to proceed for $6 \mathrm{~h}$.

The synthesized solventborne acrylic PSA was found to have the following characteristics: polymer content: $55 \mathrm{wt} \%$; viscosity: $8.1 \mathrm{~Pa}$ s; concentration of residual monomers: $<0.3 \mathrm{wt} \%$; weight average molecular weight: $M_{w}=580,000$ Dalton; number average molecular weight: $M_{n}=211,000$ Dalton; and polydispersity: $P_{d}=2.75$.

\section{Preparation of the PSA samples}

The crosslinking agent AlACA was added to the reaction vessel after the polymerization process yielded polymer levels between 0.1 and $0.5 \mathrm{wt} \%$. The solventborne model acrylic PSA containing AlACA was then coated onto a polyester film $(36 \mu \mathrm{m})$ using a laboratory film applicator DWT/EC-C109 (BASF) at a controlled coat weight of $120 \mathrm{~g} / \mathrm{m}^{2}$ (corresponding to an adhesive film thickness of $1.2 \mathrm{~mm}$ ). The film was dried at $105^{\circ} \mathrm{C}$ for $10 \mathrm{~min}$ in a laboratory oven. The dried PSA acrylic layer was then covered with the adhesive silicone paper.

\section{Testing methods}

Tack was measured using the FINAT FTM9 standard. A specimen $25 \times 175 \mathrm{~mm}^{2}$ in area was cut and formed into a loop. A loop, with the adhesive side facing out, was formed and placed in the upper grip of a Zwick/ Roell Z1.0 tensile machine. The loop was then brought into contact with a substrate mounted onto a loop tack fixture inserted into the bottom grip. Once the loop had made contact with a $25 \times 25 \mathrm{~mm}^{2}$ surface area of the substrate, the upper grip was raised at a crosshead speed of $300 \mathrm{~mm} / \mathrm{min}$. The maximum force required to remove the specimen was recorded as the loop tack. Before performing the test, the adhesive-coated strips were stored for 7 days at room temperature and $50 \%$ relative humidity. Five samples were tested, and the tack value was calculated as the arithmetic mean of the results.

The SFE of each substrate-adhesive film $(0.3 \%$ AlACA) was determined based on the equilibrium contact angles measured using distilled water, diiodomethane ( $>99.0$; Aldrich), and formamide ( $>99.5$; Aldrich). The contact angles were estimated using an optical goniometer Cobrabid Optica (Poland) equipped with an image analysis attachment. Contact angles were automatically calculated from a digitalized image by geometrical analysis of the test liquid drops $(5 \mu \mathrm{L})$ using a home-built analysis program based on Young's equation. The measurements for each sample were obtained, and the average value was calculated based on a total of nine readings. All measurements were performed at $22^{\circ} \mathrm{C}$. The SFE values were evaluated using the OW and vOCG methods. The methods have been analyzed and compared by Żenkiewicz in reference (12)

The OW method defines the SFE $\left(\gamma_{\mathrm{S}}\right)$ as the sum of the dispersion $\left(\gamma_{\mathrm{D}}\right)$ and polar $\left(\gamma_{\mathrm{P}}\right)$ components, as given in equation (3):

$0.5 \gamma_{\mathrm{L}}\left(1+\cos \Theta_{\mathrm{L}}\right)=\left(\gamma_{\mathrm{SD}} \gamma_{\mathrm{LD}}\right)^{0.5}+\left(\gamma_{\mathrm{SP}} \gamma_{\mathrm{LP}}\right)^{0.5}$

where $\gamma_{\mathrm{SD}}, \gamma_{\mathrm{LD}}$; and $\gamma_{\mathrm{SP}}, \gamma_{\mathrm{LP}}$ are the dispersion and polar components of the solid and probe liquid, respectively. $\gamma_{L}$ represents the SFE of the probe liquid, and $\Theta_{L}$ represents the contact angle. The presence of both the polar and dispersion terms requires a minimum of two probe liquids for calculation of the total SFE and its specific components. ${ }^{12}$

The SFE calculated according to the vOCG method was composed of two parts: the Lifshitz van der Waals (LW) component, $\gamma_{\mathrm{SLW}}$, and the acid-base (AB) component, $\gamma_{\mathrm{SAB}}$. The latter is equal to twice the geometrical mean of the acid $\left(\gamma_{S}^{+}\right)$and base $\left(\gamma_{S}^{-}\right)$interactions. The SFE value is generally composed of three elements. Thus, three measuring liquids are required to measure the contact angles. Using the notation used in the OW method and the same three liquids, the vOCG model may be expressed as follows:

$$
0.5 \gamma_{\mathrm{L}}\left(1+\cos \Theta_{\mathrm{L}}\right)=\left(\gamma_{\mathrm{SLW}} \gamma_{\mathrm{LLW}}\right)^{0.5}+\left(\gamma_{\mathrm{S}}^{+} \gamma_{\mathrm{L}}^{-}\right)^{0.5}+\left(\gamma_{\mathrm{S}}^{-} \gamma_{\mathrm{L}}^{+}\right)^{0.5}
$$

where $\gamma_{\text {SLW }}$ and $\gamma_{\text {LLW }}$ are the LW components of the SFE of the solid and probe liquid, respectively. $\gamma_{S}^{+} \gamma_{S}^{-}$ and $\gamma_{L}^{+} \gamma_{L}^{-}$represent the acid and base components of SFEs of the solid and probe liquid, respectively. A minimum of three probe liquids is required to calculate the total SFE and its specific components using this method. ${ }^{12}$ 


\section{Results and discussion}

The substrate material used in the tack test and the substrate SFE strongly influenced the adhesion of the PSAs. A model for the adhesion between the PSA and each substrate may be modeled based on a systematic investigation of the influence of the SFE on the tack performance. Several recent studies of the adhesion of PSAs to different substrates ${ }^{13-15}$ have been reported. In the majority of cases, only two types of substrate were studied: stainless steel and polyolefins (PE, PP). References (16) and (17) report adhesion measurements conducted using polyester, PC, glass, and $\mathrm{Si}$ wafer substrates. Several attempts have been made to study the influence of the PSA composition on the SFE and adhesive performance. ${ }^{18,19}$

Here, the tack of a PSA was measured on each of seven different substrates: stainless steel, PE, PP, PTFE, PC, PMMA, and glass. The SFE of each substrate was determined by measuring the contact angles of water, formamide, and diiodomethane. These data were then analyzed using the relations described in the above theoretical section to calculate the SFE values according to the OW method. The calculations were based on two pairs of probe liquids (water/ diiodomethane and formamide/diiodomethane) to avoid SFE estimation errors. The accuracy of the SFE values obtained from the OW model was estimated by comparison to the SFE values calculated based on the vOGC method. The contact angles and SFE calculation results are listed in Table 1. Table 1 also includes several values reported in the references (16), (17), (20-22) for comparison purposes.

On the polymeric substrates, a higher test liquid polarity resulted in a larger contact angle. The test liquid polarity increased in the following order: diiodomethane $<$ formamide $<$ water. The contact angles and SFE values of the investigated substrates were found to be inversely proportional. The SFE values of the polymeric samples increased in the following order: PTFE $<$ PP $<$ PE $<$ PC $<$ PMMA. The contact angles on the glass, estimated based on diiodomethane, were higher $\left(42.65^{\circ}\right)$ than in the case of the more polar test liquids: formamide $\left(20.9^{\circ}\right)$ or water $\left(23.6^{\circ}\right)$. As a result, the glass substrate was characterized as having the highest SFE value among all materials investigated due to a high polar component $\left(\gamma_{\mathrm{SP}}\right)$. The experimental results reveal that the dispersive component $\left(\gamma_{\mathrm{SD}}\right)$ provided the greatest contribution to the total SFE of the polymer materials (Table 1 ).

The SFE values calculated according to the methods of OW and vOCG agreed well. The largest discrepancies in the SFE values were observed from the glass and steel substrates for the water/diiodomethane test liquid pair. The large polarity difference between water and diiodomethane may result in similar contact angles on the glass and steel substrates, thereby yielding different SFE values, as calculated according to the two methods (Table 1).

One of the greatest advantages of the acrylic PSAs is their ability to adhere to a wide range of materials, including low-surface energy and high-surface energy plastics, without the need for a preapplication treatment. This feature offers a significant benefit in the context of applications in which adhesion is challenging, such as on thermoplastic polyolefin substrates. The tack measurement results obtained on a variety of substrates as a function of the crosslinking density in a model acrylic PSA are presented in Fig. 1.

The experiment results revealed a clear relationship between the SFE of a substrate and the tack for the model acrylic PSA examined here. The tack values increased in the following order: $\mathrm{PTFE}<\mathrm{PP}<\mathrm{PE}<$ glass $<$ steel $<$ PC $<$ PMMA. The SFE values of the polymeric materials were $20.5 \mathrm{~mJ} / \mathrm{m}^{2}$ (PTFE) and $42.9 \mathrm{~mJ} / \mathrm{m}^{2}$ (PMMA). The corresponding tack values increased by $300-700 \%$ as a function of the crosslinking density of the model acrylic PSA. Interestingly, although the glass substrate displayed the greatest SFE value among all substrates, the tack value was moderate. These results suggested that a large substrate SFE could reduce the tack.

\section{Table 1: Contact angles and SFE values of the substrates and model acrylic PSA}

\begin{tabular}{|c|c|c|c|c|c|c|c|c|c|c|c|c|c|c|c|}
\hline \multirow[t]{3}{*}{ Sample } & \multicolumn{3}{|c|}{ Contact angle $\left({ }^{\circ}\right)$} & \multicolumn{6}{|c|}{$\begin{array}{l}\text { SFE component according } \\
\text { to OW method }\left(\mathrm{mJ} / \mathrm{m}^{2}\right)\end{array}$} & \multicolumn{5}{|c|}{$\begin{array}{l}\text { SFE component according } \\
\text { to vOCG method }\left(\mathrm{mJ} / \mathrm{m}^{2}\right)\end{array}$} & \multirow{3}{*}{$\begin{array}{l}\text { SFE from } \\
\text { literature } \\
\left(\mathrm{mJ} / \mathrm{m}^{2}\right)\end{array}$} \\
\hline & \multirow[t]{2}{*}{ Diiodomethane } & \multirow[t]{2}{*}{ Formamide } & \multirow[t]{2}{*}{ Water } & \multicolumn{3}{|c|}{$\begin{array}{c}\text { Water/ } \\
\text { diiodomethane }\end{array}$} & \multicolumn{3}{|c|}{$\begin{array}{c}\text { Formamide/ } \\
\text { diiodomethane }\end{array}$} & \multicolumn{5}{|c|}{$\begin{array}{l}\text { Water/formamide/ } \\
\text { diiodomethane }\end{array}$} & \\
\hline & & & & $\gamma_{\mathrm{SP}}$ & $\gamma_{S D}$ & $\gamma_{S}$ & $\gamma_{S P}$ & $\gamma_{S D}$ & $\gamma_{S}$ & $\gamma_{\text {SLW }}$ & $\gamma_{\mathrm{s}}^{-}$ & $\gamma_{s}^{+}$ & $\gamma_{S A B}$ & $\gamma_{S}$ & \\
\hline PTFE & 74.5 & 88.3 & 106.1 & 0.6 & 19.8 & 20.4 & 0.1 & 20.7 & 20.8 & 20.4 & 0.0 & 1.0 & 0.0 & 20.4 & $19.0-20.0^{20}$ \\
\hline $\mathrm{PP}$ & 55.3 & 72.4 & 91.7 & 2.0 & 29.3 & 31.3 & 0.5 & 31.1 & 31.6 & 31.3 & 0.0 & 3.2 & 0.0 & 31.3 & $31.2-33.8^{16}$ \\
\hline PE & 50.8 & 67.1 & 83.8 & 4.2 & 30.3 & 34.5 & 1.1 & 32.8 & 33.9 & 33.8 & 0.0 & 6.8 & 0.0 & 33.8 & $30.0-31.0^{20}$ \\
\hline PC & 49.2 & 56.6 & 79.0 & 6.1 & 30.1 & 36.2 & 5.9 & 30.2 & 36.1 & 34.7 & 0.5 & 5.9 & 3.5 & 38.2 & $35.0^{21}$ \\
\hline PMMA & 34.6 & 52.3 & 70.1 & 8.4 & 36.1 & 44.5 & 3.0 & 39.2 & 42.2 & 42.1 & 0.0 & 12.4 & 0.0 & 42.1 & $42.3^{22}$ \\
\hline Steel & 47.6 & 55.5 & 59.1 & 18.8 & 26.6 & 45.4 & 5.9 & 31.1 & 37.0 & 35.6 & 0.0 & 29.1 & 0.0 & 35.6 & $43.0^{17} ; 46.0^{23}$ \\
\hline Glass & 42.7 & 20.9 & 23.6 & 43.1 & 24.0 & 67.1 & 30.5 & 26.3 & 56.8 & 38.2 & 1.2 & 49.0 & 15.4 & 53.6 & $68.0^{17} ; 65.0^{23}$ \\
\hline Adhesive ${ }^{a}$ & 57.8 & 72.4 & 88.2 & 3.4 & 27.3 & 30.7 & 1.8 & 27.4 & 29.2 & 27.5 & 0.2 & 4.8 & 2.0 & 29.5 & - \\
\hline
\end{tabular}

a Model acrylic PSA containing $0.3 \%$ AIACA 
Tack performance was strongly influenced by the crosslinker concentration. As shown in Fig. 1, the tack decreased as the concentration of AlACA in the PSA increased. The extent of crosslinking in the model acrylic PSA changed the mechanism of debonding and produced a failure mode transformation. Three tests are typically used to characterize the failure mode of an adhesive PSA joint: (1) cohesive failure is characterized by the failure of the adhesive itself; (2) adhesive failure is characterized by the failure of a joint at the adhesive/substrate interface; and (3) mixed failure occurs when a crack propagates over a region both in the adhesive (cohesive failure) and at the interface (adhesive failure). On PTFE, PP, and PE adhesive failure alone was observed during the loop tack test. The PC, PMMA, steel, and glass substrates, in the presence of PSAs prepared with crosslinker concentrations of $0.0-1.0 \%$, displayed cohesive failure. At crosslinker concentrations exceeding $0.1 \%$, the failure mode changed from cohesive to adhesive failure, and the tack decreased significantly (Fig. 1).

It should be noted that the substrate roughness may influence the tack results. In contrast to the trends observed among all other classes of adhesives, the use of a rough substrate reduces the adhesion of a PSA to the substrate. ${ }^{24}$ This effect results from the presence of asperities, which reduce the size of the actual contact area with the polymer. The effects of the roughness increase with the elastic modulus of the polymer film. ${ }^{25,26}$ The strength of an adhesive bond directly or indirectly reflects the energy dissipated in the joint as a whole during failure. Surface roughness can increase this energy dissipation by increasing the tack. ${ }^{27}$

In the present study, a large adhesive layer coat weight of the model acrylic PSA $\left(120 \mathrm{~g} / \mathrm{m}^{2}\right)$ was

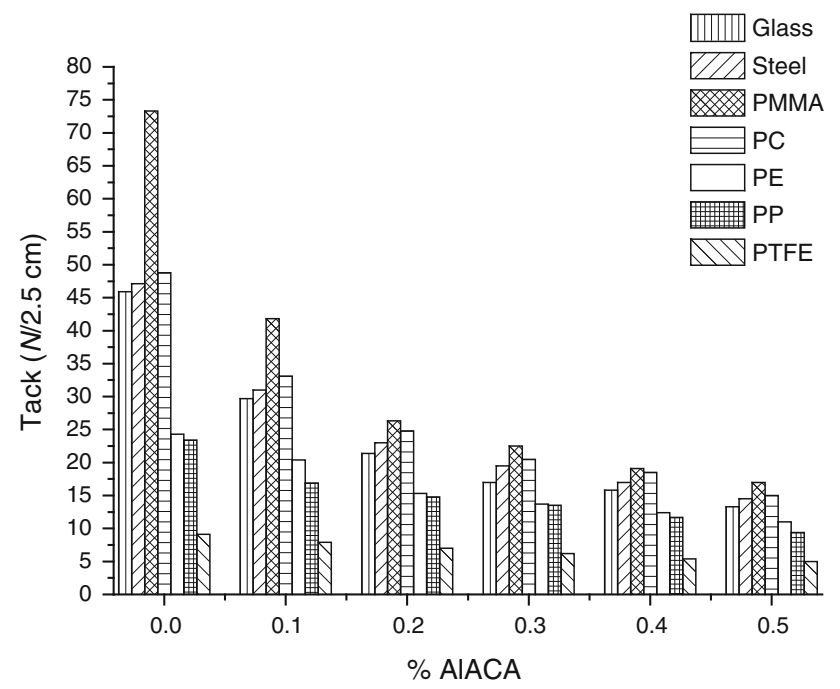

Fig. 1: Tack of a model acrylic PSA as a function of the AIACA concentration and substrate type. Coating weight $120 \mathrm{~g} / \mathrm{m}^{2}$ selected in an effort to minimize the effects of surface roughness on the adhesion properties.

The influence of the substrate SFE ( $\left.\gamma_{\text {substrate }}\right)$ on tack (at a constant adhesive SFE, $\gamma_{\text {adhesive }}$ ) was investigated as follows. SFE values were calculated based on the vOCG and OW models for a given material and model acrylic PSA (containing 0.3\% AlACA). An average SFE was calculated and compared with the corresponding tack results. The dependence of the tack on the SFE is shown in Fig. 2.

The experimental results reported here confirm that the difference between the SFE values of a substrate and adhesive $\left(\Delta_{\mathrm{SFE}}\right)$ is a crucial factor governing the tack of an acrylic PSA. Figure 2 shows that a system in which $\gamma_{\text {substrate }}$ is much lower than $\gamma_{\text {adhesive }}$ (i.e., PTFE) displays incomplete wetting and a low tack value. A system in which $\gamma_{\text {substrate }}$ is slightly greater than $\gamma_{\text {adhesive }}$ (i.e., PP and PE) displays an intermediate tack value. The best tack was observed in systems in which $\gamma_{\text {substrate }}$ clearly exceeded $\gamma_{\text {adhesive }}$ (i.e., steel, PC, PMMA, glass). An optimal tack performance in a model acrylic PSA containing $0.3 \%$ AlACA was achieved for a $\Delta_{\mathrm{SFE}}$ of $7.0-13.1 \mathrm{~mJ} / \mathrm{m}^{2}$ (steel, PC, and PMMA). $\Delta_{\mathrm{SFE}}$ values exceeding $29.4 \mathrm{~mJ} / \mathrm{m}^{2}$ clearly reduced the tack, as observed in the case of the glass substrate (Fig. 2).

The formation of chemical bonds at the interface between two materials may be quantified by measuring the thermodynamic work of adhesion $\left(W_{\mathrm{a}}\right)$. The viscoelastic character of the PSA adhesive required the application of an external force to achieve complete wetting of the substrate. Good wetting was obtained for systems comprising (1) an adhesive with a low resistance to flow and (2) a substrate with interfacial properties that permitted the spreading of the adhesive over the contact area. The flow resistance corresponded to the rheological properties of the

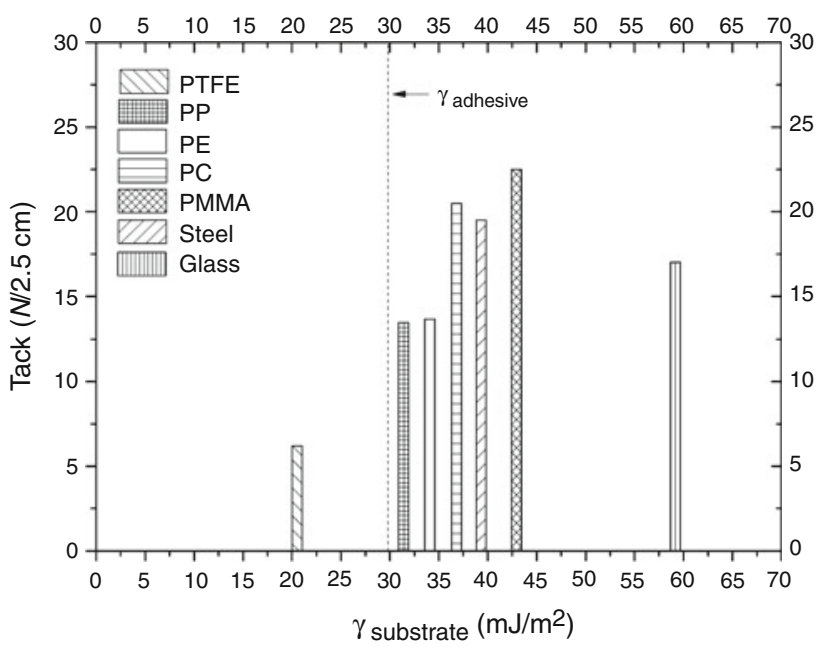

Fig. 2: Tack of a model acrylic PSA (0.3\% AIACA) on several substrates vs the corresponding material SFE ( $\left.\gamma_{\text {substrate }}\right)$ at a constant adhesive SFE ( $\left.\gamma_{\text {adhesive }}\right)$ 
Table 2: Thermodynamic $\left(W_{\mathrm{a}}\right)$ and total $\left(W_{\mathrm{T}}\right)$ work values for the adhesion during separation of an adhesive tape coated with a model acrylic PSA containing $0.3 \%$ AIACA from a variety of substrates

\begin{tabular}{lcccc} 
Substrate & $W_{\mathrm{a}}\left(\mathrm{mJ} / \mathrm{m}^{2}\right)$ & $W_{\mathrm{T}} \times 10^{3}\left(\mathrm{~mJ} / \mathrm{m}^{2}\right)$ & $\frac{W_{\mathrm{T}}}{W_{\mathrm{a}}}$ & Tack $(N / 2.5 \mathrm{~cm})$ \\
\hline PTFE & 48.3 & 248 & 5,135 & 6.2 \\
PP & 60.3 & 540 & 8,955 & 13.5 \\
PE & 63.3 & 548 & 8,657 & 13.7 \\
PC & 70.1 & 832 & 11,869 & 20.8 \\
PMMA & 71.2 & 900 & 12,640 & 22.5 \\
Steel & 67.4 & 776 & 11,513 & 19.4 \\
Glass & 75.9 & 696 & 9,170 & 17.4 \\
\hline
\end{tabular}

polymers used in the PSA formulation. ${ }^{28}$ The total work involved in peeling may be expressed according to the equation:

$W_{\mathrm{T}}=W_{\mathrm{a}}(1+\Phi)$,

where $W_{\mathrm{a}}$ and $W_{\mathrm{T}}$ are the thermodynamic and total works of adhesion, respectively, and $\Phi$ is a dissipation factor. ${ }^{29} W_{\mathrm{a}}$ indicates the change in the SFE as a result of contact between the materials. This value equals the amount of work expended under reversible or equilibrium conditions to disrupt the interface. $W_{\mathrm{a}}$ is related to the SFE by the Dupré equation. ${ }^{30} \gamma_{\mathrm{SAB}}$ and $\gamma_{\text {SLW }}$ may be included in the expression for the work of adhesion $W_{\mathrm{a}}$ according to:

$$
\begin{aligned}
W_{\mathrm{a}}= & 2\left(\gamma_{\mathrm{SLW}(\mathrm{adh})} \gamma_{\mathrm{SLW}(\mathrm{sub})}\right)^{0.5} \\
& +2\left(\gamma_{\mathrm{S}(\mathrm{adh})}^{-} \gamma_{\mathrm{S}(\mathrm{sub})}^{+}\right)^{0.5}\left(\gamma_{\mathrm{S}(\mathrm{adh})}^{+} \gamma_{\mathrm{S}(\mathrm{sub})}^{-}\right)^{0.5}
\end{aligned}
$$

The subscripts adh and sub refer to the adhesive and substrate, respectively. ${ }^{31}$

The thermodynamic work of adhesion (according to equation (6)) and total work of adhesion $\left(W_{\mathrm{T}}\right)$ on substrates used in tack measurements were evaluated. The calculations of $W_{\mathrm{a}}$ utilized the vOCG method results for the substrates and the model acrylic PSA containing $0.3 \%$ AlACA. $W_{\mathrm{T}}$ was computed using equation $(7)^{32}$ :

$W_{\mathrm{T}}=\frac{F}{b}(1-\cos \Theta)$,

where $F, b$, and $\Theta$ are the tack force, tape width, and peel angle, respectively. The results are listed in Table 2.

In general, the various substrates displayed small differences in the $W_{\mathrm{a}}$ values, indicating that the substrates displayed similar tendencies toward forming chemical bonds with the model acrylic PSA. As expected, the lowest $W_{\mathrm{a}}$ value among the substrates was observed for the PTFE substrate, and the highest $W_{\mathrm{a}}$ of adhesion was observed for the glass substrate. Calculations showed that $W_{\mathrm{a}}$ of the adhesives joints increased with the SFE of the substrates. The values of $W_{\mathrm{T}}$ were much larger than the corresponding $W_{\mathrm{a}}$ values. For instance, the energy of peeling from the PMMA substrate was 12,640 times higher than the corresponding $W_{\mathrm{a}}$ on the PTFE substrate, and yielded a value of $W_{\mathrm{T}}$ that was 5135 times the value $W_{\mathrm{a}}$ (Table 2). This result suggested that during the loop tack test, the system dissipated a significant amount of viscoelastic energy due to deformation of the adhesive layer. This energy consumption may explain the large discrepancies between the tack values despite the small differences in $W_{\mathrm{a}}$ for a given system. It should be noted that the viscoelastic energy dissipation could not be quantified here, and the tack energy could not be decomposed into the $W_{\mathrm{a}}$ and viscoelastic energy consumption contributions.

\section{Conclusions}

The experiments conducted here revealed a clear relationship between the substrate SFE $\left(\gamma_{\text {substrate }}\right)$ and the tack of a model acrylic PSA. For the polymeric substrates, an increase of $\gamma_{\text {substrate }}$ from 20.5 to $42.9 \mathrm{~mJ} / \mathrm{m}^{2}$ (at a constant adhesive SFE) increased the tack by about $300-700 \%$, depending on the crosslinking density of the model acrylic PSA. The difference between the SFE values of the substrate and PSA $\left(\Delta_{\mathrm{SFE}}\right)$ were crucial to the tack measurements, which has significant practical implications. The model acrylic PSA containing $0.3 \%$ AlACA yielded an optimal tack performance for $\Delta_{\mathrm{SFE}}$ values between 7.0 and $13.1 \mathrm{~mJ} / \mathrm{m}^{2}$. We clearly showed that the relationship between the tack and the thermodynamic work of adhesion associated with the separation of an adhesive tape from a substrate is weak. Tack was found to depend strongly on the factors associated with energy dissipation. The adhesive system displayed a maximum tack on a high-surface energy substrate.

Open Access This article is distributed under the terms of the Creative Commons Attribution License which permits any use, distribution, and reproduction in any medium, provided the original author(s) and the source are credited. 


\section{References}

1. Creton, C, "Pressure-Sensitive Adhesives: An Introductory Course." MRS Bull., 28 (6) 434-439 (2003)

2. Czech, Z, Kowalski, A, Ortyl, J, "Tack of Pressure-Sensitive Adhesives (PSAs)." Coating, 1 1-4 (2011)

3. Dahlquist, C, "Creep." In: Satas, D (ed.) Handbook of Pressure-Sensitive Adhesive Technology 3rd, pp. 121-138. Satas \& Associates, Warwick (1999)

4. Li, L, Tirrell, M, Korba, G, Pocius, A, "Surface Energy and Adhesion Studies on Acrylic Pressure-Sensitive Adhesives." J. Adhesion, 76 (4) 307-334 (2001)

5. Anonymous, "Bonding Low Surface Energy Plastics." Machine Des., June 15 118-120 (2000)

6. Duncan, B, Mera, R, Leatherdale, D, Taylor, M, Musgrove, $\mathrm{R}$, "Techniques for Characterizing the Wetting, Coating and Spreading of Adhesives on Surfaces." National Physical Laboratory Report, DEPC MPR 020 March (2005)

7. Żenkiewicz, M, "Methods for the Calculation of Surface Free Energy of Solids." J. Achiev. Mater. Manuf. Eng., 24 (1) 137-145 (2007)

8. Zosel, A, "Adhesion and Tack of Polymers: Influence of Mechanical Properties and Surface Tensions." Colloid Polym. Sci., 263 (7) 541-553 (1985)

9. Kranceski, M, Johnson, J, Temin, S, "Chemical and Physical Factors Affecting Performance of Pressure-Sensitive Adhesives." J. Macromol. Sci. C: Polym. Rev., 26 (1) 143-182 (1986)

10. Baldan, A, "Adhesion Phenomena in Bonded Joints." Int. J. Adhesion Adhesives, 38 95-116 (2012)

11. Toyama, M, Ito, T, Nukatsuka, H, Ikeda, M, "Studies on Tack of Pressure-Sensitive Adhesive Tapes: On the Relationship Between Pressure-Sensitive Adhesion and Surface Energy of Substrates." J. Appl. Polym. Sci., 17 3495-3502 (1973)

12. Żenkiewicz, M, "Comparative Study on the Surface Free Energy of a Solid Calculated by Different Methods." Polym. Test., 24 (1) 14-19 (2007)

13. Jovanović, R, Dubé, R, "Screening Experiments for Butyl Acrylate/Vinyl Acetate Pressure-Sensitive Adhesives." Ind. Eng. Chem. Res., 44 6668-6675 (2005)

14. Deplace, F, Carelli, C, Mariot, S, Retsos, H, Chateauminois, A, Ouzineb, K, Creton, C, "Fine Tuning the Adhesive Properties of a Soft Nanostructured Adhesive with Rheological Measurements." J. Adhesion, 85 (1) 18-54 (2009)

15. Carelli, C, Déplace, F, Boissonnet, L, Creton, C, "Effect of a Gradient in Viscoelastic Properties on the Debonding Mechanisms of Soft Adhesives." J. Adhesion, 83 (5) 491505 (2007)

16. Okamatsu, T, Yasuda, Y, Ochi, M, “Thermodynamic Work of Adhesion and Peel Adhesion Energy of DimethoxysilylTerminated Polypropylene Oxide/Epoxy Resin System Jointed with Polymeric Substrates." J. Appl. Polym. Sci., 80 (11) 1920-1930 (2001)

17. Peykova, Y, Lebedeva, O, Diethert, A, Müller-Buschbaum, P, Willenbacher, N, "Adhesive Properties of Acrylate
Copolymers: Effect of the Nature of the Substrate and Copolymer Functionality." Int. J. Adhesion Adhesives, 34 107-116 (2012)

18. Taghizadeh, S, Ghasemi, D, "Rheological and Adhesion Properties of Acrylic Pressure-Sensitive Adhesives." J. Appl. Polym. Sci., 120 (1) 411-418 (2011)

19. Mahdavi, HS, Taghizadeh, S, "The Effect of Alpha Hydroxy Acids on the Tack of Pressure-sensitive Adhesive." Iran. Polym. J., 14 (4) 379-385 (2005)

20. Markgraf, D, “Surface Treatment.” In: Butler, T (ed.) Film Extrusion Manual 2nd, p. 299. TAPPI Press, Norcross, GA (2005)

21. Subedi, D, Zajickova, L, Bursikova, V, Janca J, "Surface Modification of Polycarbonate by Low Pressure RF Discharge." Proceedings of the International Workshop on Plasma Computations \& Applications, Putra Nilai, 14-15 July, 2008

22. Ozcan, C, Hasirci, N, "Evaluation of Surface Free Energy for PMMA Films.” J. Appl. Polym. Sci., 108 (1) 438-446 (2008)

23. Piau, J, Verdier, C, Benyahia, L, "Influence of Rheology and Surface Properties in the Adhesion of Uncross-Linked Pressure-Sensitive Adhesives." Rheol. Acta, 36 449-461 (1997)

24. Peykova, Y, Guriyanova, S, Lebedeva, O, Diethert, A, Moeller-Buschbaumb, P, Willenbacher, N, "The Effect of Surface Roughness on Adhesive Properties of Acrylate Copolymers." Int. J. Adhesion Adhesives, 30 (4) 245-254 (2010)

25. Creton, C, Leibrer, L, "How Does Tack Depend on Time of Contact and Contact Pressure?" J. Polym. Sci. B: Polym. Phys., 34 (3) 545-554 (1996)

26. Chung, J, Chaudhury, M, "Soft and Hard Adhesion." J. Adhesion, 81 (10-11) 1119-1145 (2005)

27. Packham, D, "The Adhesion of Polymers to Metals: The Role of Surface Topography." In: Mittal, K (ed.) Adhesion Aspects of Polymeric Coatings, pp. 19-44. Plenum Press, New York (1983)

28. Rüdenauer, Y, "Influence of Interfacial Parameters on the Adhesion of Soft Polymers." Dissertation 9-10 (2013)

29. Derail, C, Marin, G, "Role of Viscoelastic Behavior of Pressure-Sensitive Adhesives in the Course of Bonding and Debonding Processes." In: Benedek, I, Feldstein, M (eds.) Fundamentals of Pressure-Sensitivity, p. 3. CRC Press, Boca Raton (2009)

30. Packham, D, "Work of Adhesion: Contact Angles and Contact Mechanics." Int. J. Adhesion Adhesives, 16 121-128 (1996)

31. Cerne, L, Simoncic, B, Zeljko, M, "The Influence of Repellent Coatings on Surface Free Energy of Glass Plate and Cotton Fabric." Appl. Surf. Sci., 254 (20) 6467-6477 (2008)

32. Christensen, S, McKinley, G, "Rheological Modeling of the Peeling of Pressure-Sensitive Adhesives and Other Elastomers." Int. J. Adhesion Adhesives, 18 (5) 333-343 (1998) 